\title{
Carcinoma de células renales multicéntrico en injerto renal
}

\author{
Aguilera Tubet C, Gutierrez Baños JL, Del Valle Schaan JI, Martín García B, Ballestero Diego R, \\ Zubillaga Guerrero S.
}

Servicio de Urología. Hospital Universitario Marqués de Valdecilla. Santander.

Actas Urol Esp. 2007;31(5):553-555

\section{RESUMEN}

CARCINOMA DE CELULAS RENALES MULTICENTRICO EN INJERTO RENAL

El desarrollo de neoplasias después de la realización de un trasplante es un hecho conocido; pero el desarrollo de una neoplasia sobre el órgano trasplantado es raro. Las pruebas diagnósticas incluyen la ecografía rutinaria y la TC. En algunos casos seleccionados, si el injerto es funcionante y es técnicamente factible, se puede realizar cirugía conservadora de nefronas. El patrón estándar de tratamiento es la trasplantectomía.

Presentamos un caso de carcinoma renal multicéntrico en un riñón trasplantado 17 años antes.

Palabras clave: Trasplante renal. Carcinoma de células renales. Inmunosupresión.

\section{ABSTRACT}

\section{MULTIFOCAL RENAL CELL CARCINOMA ON RENAL ALLOGRAFT}

Development of neoplasms after a renal transplantation is well known, but allograft neoplasms are uncommon. Diagnostics studies include routine ultrasonography, and CT. In some selective cases, if the graft is functionally salvageable and it is technically feasible, a nephron-sparing surgery should be performed. In any case, standard intervention is nephrectomy.

We report a case of multifocal renal cell carcinoma diagnosed in a kidney grafted 17 years before. Keywords: Renal allograft. Renal cell carcinoma. Inmunosuppression.

$\mathrm{E}$ trasplante renal es el tratamiento de elección en los pacientes con enfermedad renal terminal. La inmunosupresión hace a estos pacientes más susceptibles de padecer infecciones y tumores que la población general.

La incidencia de tumores malignos en los receptores de injertos renales después de 10 años del trasplante es aproximadamente del $20 \%$, que es 10 veces superior a la de la población general ${ }^{1}$. La mayoría de los tumores de células renales ocurren en los riñones propios, tan solo el $4,8 \%$ ocurren en el riñón trasplantado 2 .

Aunque estos tumores en injertos renales, presentan una evolución más lenta que en otra localización, es importante su rápida detección debido a las consecuencias de un diagnóstico tardío.

\section{CASO CLINICO}

Presentamos el caso de la aparición de varias formaciones nodulares de supuesto origen neoplásico en un riñón trasplantado 17 años antes. Se trata de un varón de 46 años que recibió un trasplante de riñón de donante cadáver hace 17 años debido a una insuficiencia renal terminal originada por una hialinosis focal y segmentaria. Sigue una pauta de inmunosupresión con prednisona y ciclosporina. El paciente permaneció un año en programa de hemodiálisis antes del trasplante.

Durante estos 17 años desarrolla una nefropatía crónica del injerto y en el seno de un deterioro de sus cifras de función renal basal, se realiza una ecografía urológica, descubriendo una formación nodular sólida de $35 \mathrm{~mm}$ de diámetro 
mayor, con flujos en su interior, sugestivo de proceso neoformativo (Fig. 1).

Se realiza estudio de extensión, con un TAC torácico negativo para metástasis pulmonares y un rastreo óseo corporal total en el que no se ponen en evidencia lesiones óseas. En el TAC abdominal efectuado para un mejor estudio del nódulo del injerto se objetiva la presencia de dos formaciones nodulares corticales, bien definidas de 24 y $30 \mathrm{~mm}$, sólidas y con captación de contraste de forma homogénea. También se observan varias lesiones nodulares pequeñas por todo el injerto, que al ser de muy pequeño tamaño no se puede determinar si tienen un patrón quístico o sólido. No se observan adenopatías abdominopélvicas ni metástasis a otro nivel (Fig. 2).

Ante el hallazgo de dos lesiones nodulares y múltiples lesiones hipodensas de dudosa etiología, se decide la realización de trasplantectomía.

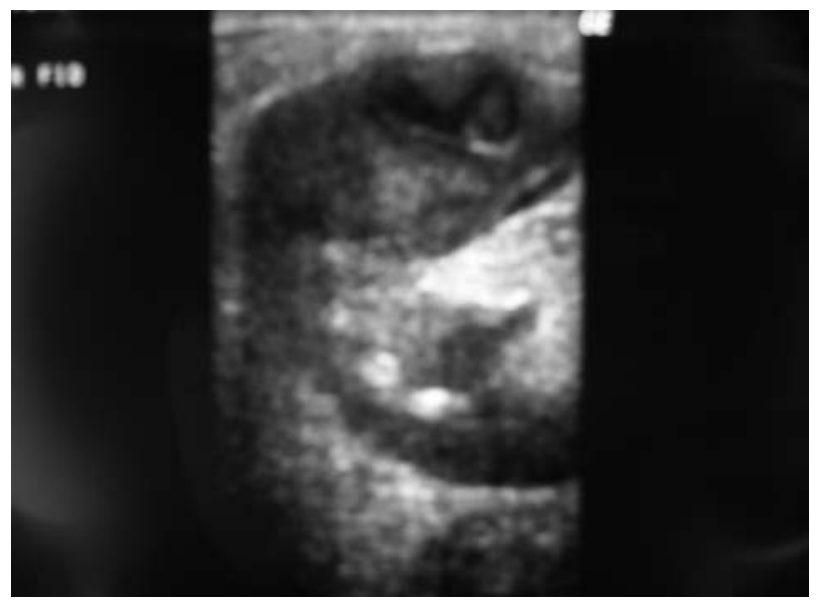

FIGURA 1

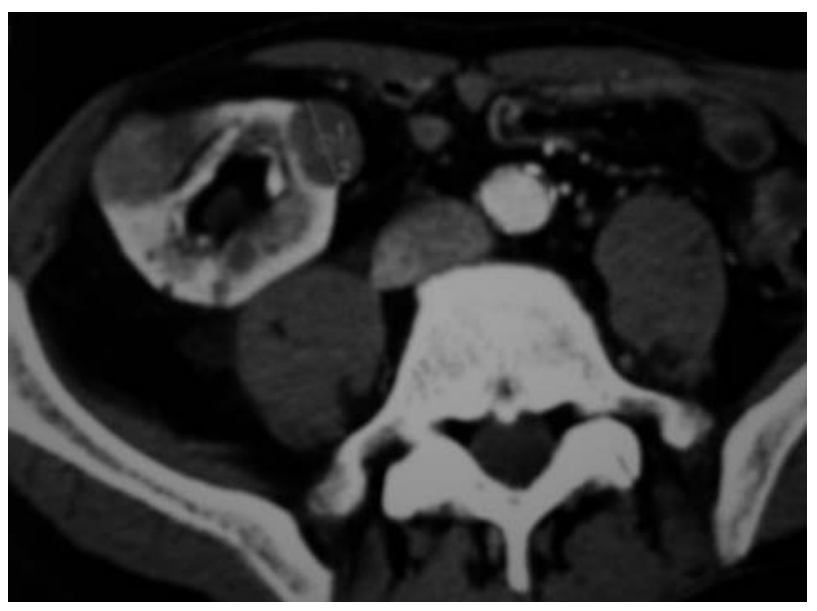

FIGURA 2
Durante el acto quirúrgico se observan múltiples tumoraciones dispersas por la superficie del injerto renal.

La anatomía patológica de la pieza se informa como carcinoma de células renales de tipo papilar multifocal de grado 1 de Führman que infiltra la cápsula renal y respeta el borde quirúrgico de resección en cuatro formaciones nodulares amarillentas, adenomas papilares múltiples y nefropatía crónica del trasplante grado III de la clasificación de Banff del año 97.

El curso postoperatorio fue satisfactorio no existiendo complicaciones derivadas de la cirugía y retornando el paciente al programa de hemodiálisis. Lleva seis meses de seguimiento sin evidencia de recurrencia local ni aparición de metástasis a distancia.

\section{DISCUSIÓN}

La enfermedad cardiovascular y los procesos malignos, son los principales responsables de la morbilidad y mortalidad del trasplante renal. Penn realizó una revisión del Registro de tumores en trasplantados de Cincinnati y de la literatura, recogiendo un total de 9.688 casos de cáncer desarrollados en 9.032 receptores de un injerto renal. La mayoria eran procesos linfoproliferativos, tumores cutáneos, carcinomas de la vulva y del periné, carcinomas in situ del cerviz y útero, sarcomas de Kaposi, carcinoma hepatocelular y carcinoma de células renales. Los tumores de células renales constituyen el $4.6 \%$ de procesos malignos en los receptores de un injerto renal, pero la mayoría de los casos ocurre en los riñones propios y menos del $10 \%$ afectan al injerto ${ }^{2}$.

El origen del tumor en el injerto puede ser: de novo, transferencia desde el donante, secundario o metastásico (siendo este el más usual).

Muchos factores pueden contribuir al desarrollo de neoplasias en pacientes trasplantados. La inmunosupresión juega el mayor papel, debido a la alteración de los mecanismos de identificación y destrucción de células malignas. La estimulación antigénica crónica por parte del injerto o las infecciones crónicas pueden inducir la proliferación linfocítica y llevar al desarrollo de síndromes linfoproliferativos. Los oncogenes víricos también están implicados en el desarrollo de neoplasias. Los linfomas no Hodgkin y el carcinoma in situ 
de cérvix están relacionados con el virus de Epstein-Barr y el del papiloma humano ${ }^{3}$.

Los carcinomas de células renales en riñones trasplantados son menos agresivos que los aparecidos en los riñones propios. En un adulto que recibe un trasplante de donante cadáver, en donde existe la probabilidad de tumor en el momento del trasplante, la progresión tumoral esta calculada en $0,5 \mathrm{~cm}$ al año ${ }^{4}$.

$\mathrm{El}$ diagnóstico de estos tumores ha de hacerse dentro del normal seguimiento de estos pacientes, ya que, debido a la incidencia tan alta de neoplasias, se deberá realizar un control estrecho asistido por la imagen, en la mayor parte de los casos la ecografía será suficiente.

El tratamiento variará en función de las características del tumor y su tamaño. Hasta ahora en la mayor parte de los pacientes se realizaba la nefrectomía del injerto con lo que retornaban de nuevo al tratamiento sustitutivo. En los últimos años está cambiando la manera de proceder con estos tumores realizándose cirugía preservadora de nefronas en aquellos casos en que por un tamaño pequeño, situación excéntrica del tumor o un buen aporte sanguíneo al resto del parénquima del injerto, esté indicada. Si se realiza un seguimiento estrecho de estos pacientes, la calidad de vida ganada al no retornar a la hemodiálisis, justifica este tipo de cirugía ${ }^{5-8}$. En cualquier caso, debe ser un abordaje extracapsular, con resección en bloque del tumor, del tejido circundante, adenopatías y los vasos del injerto renal desde el punto de su anastomosis mejor que desde el hilio.

Existen grupos que también están empleando procedimientos mínimamente invasivos para tratar este tipo de tumores; ablación por radiofrecuencia $^{9}$ y crioablación percutanea ${ }^{10}$.
En nuestro caso, al tratarse de varios tumores en el injerto, se optó por la nefrectomía debido al escaso parénquima sano que conservar, y el difícil cumplimiento de los criterios oncológicos si en este caso se hubiera realizado cirugía preservadora de nefronas.

\section{REFERENCIAS}

1. Lutz J, Heemann U. Tumors after kidney transplantation. Curr Opin Urol. 2003;13(2): 105-109.

2. Penn I. Primary kidney tumors before and after renal transplantation. Transplantation 1995;59(4):480-485.

3. Krishnamurthi V, Novick A. Nephron-sparing surgery in a renal allograft. Urology 1997;50(1):132-134.

4. Heinz-Peer G, Helbich T, Nottling B, Klauser R, Muhlbacher F, Hubsch P. Renal cell carcinoma in an allograft kidney transplant. Transplantation 1994;57(3):475478.

5. Mindrup S, Rayhill S, Fallon B. Renal cell carcinoma in a transplanted kidney. J Urol 2001;165(6Pt1):1990.

6. Schostak M, Heicappell R, Sauter T, Goessl C, Krause H, Hoyer $\mathrm{J}$ et al. Renal cell carcinoma in a kidney transplant: allogeneic genome in the tumor justifies organ-preserving surgery. Transplant Proc 2002;34(6):2231-2232.

7. Kim JY, Ruckle HC, Ramin SA. Partial nephrectomy for renal cell carcinoma in an allograft kidney 15 years after transplantation. J Urol 2001;165(4): 1205.

8. Siebels M, Theodorakis J, Liedl B, Schneede P, Hofstetter A. Large de novo renal cell carcinoma in a 10-year-old transplanted kidney: successful organ-preserving therapy. Transplantation 2000;69(4):677-679.

9. Baughman SM, Sexton WJ, Glanton CW, Dalrymple NC and Bishoff JT. Computerized tomography guided radio frequency ablation of a renal cell carcinoma within a renal allograft. J Urol 2004;172(4Pt1):1262-1263.

10. Shingleton WB, Sewell PE. Percutaneous cryoablation of renal cell carcinoma in a transplanted kidney. BJU Int 2002;90(1):137-138.

Correspondencia autora: C. Aguilera Tubet

Servicio de Urología. Hospital Universitario Marqués de Valdecilla. Avda. de Valdecilla, s/n. 39008 Santander Tel.: 942202520

E-mail autora: car1677@hotmail.com

Información artículo: Nota clínica

Trabajo recibido: febrero 2006

Trabajo aceptado: abril 2006 